\title{
A Clinical Study of Lichtenstein Tension-Free Prolene Mesh Hernioplasty in Cases of Inguinal Hernia
}

\author{
Trishant Jaykar Chotai, Vijay Kanase \\ Department of Surgery, Krishna Institute of Medical Sciences Deemed University, Karad
}

\begin{abstract}
Background: Main reason for intervention in inginal hernia was continuous growth of inguinal and scrotal swelling, the risk of incarceration and bad results of conservative methods like truss placement. Surgical techniques have evolved rapidly since Edoardo Bassini proposed his first successful reconstruction of the inguinal floor. Various adaptations of his technique did however not result in substantial reduction in number of recurrences. The danger of high recurrence rate that had loomed low over the heads of hernia surgeons in the past had been dissipated by the advent of Lichtenstein tension-free prolene mesh inguinal hernia repair. Methods: 50 patients were subjected to prolene mesh of which 5 patients underwent bilateral repair of inguinal hernia. The follow up and pre-operative investigations were done on O.P.D basis. All elective patients were admitted a day prior to surgery. The patients were kept nil by mouth overnight. Spinal anaesthesia was used in all cases. Post-operative antibiotics were given and analgesics were given on demand basis. All except one patient were discharged on 3rd post-operative day. Results: Inguinal hernias were found to be more common in males (98\%) than females. $28 \%$ patients were found in the age group 61-70 years. $60 \%$ operated hernias were indirect type,36.38\% operated hernias were of direct type, while $1.81 \%$ pantaloons and $1.81 \%$ recurrent inguinal hernias were subjected to prolene mesh repair. $81.82 \%$ hernias were incomplete while $18.18 \%$ hernias were complete. $98.19 \%$ hernias on clinical presentation were reducible and $1.81 \%$ presented as obstructed inguinal hernia. Hypertension (12\%) was the most common co-morbid condition encountered in our study. Only one patient in our study (1.81\%) developed localized subcutaneous infection, only one patient (1.81\%) developed testicular pain which was due to scrotal oedema. One $(1.81 \%)$ patient in our series complained pain in operative region which lasted not more than 2 months and was subsided by analgesics. 98\% patients were discharged on 3rd post-oprerative day. Conclusion: Lichtenstein repair has become gold standard in hernia surgery. The repair is physiologically sound as it buttresses the posterior wall of inguinal canal, weakness of which is the reason behind development of inguinal hernia. The repair has a very short learning curve with high degree of reproducibility. Prolene mesh repair does not result in higher rate of infection. Tension-free nature of the repair which we used, results in reduced pain in post-operative period. We could not find a single case of recurrence. Considering the wide range of advantages this repair secures for the patient, the cost of prolene mesh seems nominal only.
\end{abstract}

Keywords: inguinal hernia , prolene mesh, Lichtenstein repair, recurrence

\section{Introduction}

Inguinal hernia most probably has been a disease ever since mankind existed. In view of its existence in different kinds of animals, and in particular of primates, one can assume that already prehistoric human beings were affected with the disease. Inguinal hernia repair has made enormous changes throughout ages. The main reason for intervention however remained the same: continuous growth of inguinal and scrotal swelling, the risk of incarceration of the hernia content and the bad results of conservative methods like truss placement. Surgical techniques have rapidly evolved since EdoardoBassini proposed his first successful reconstruction of the inguinal floor. Various adaptations of his technique did however not result in substantial reduction in number of recurrences. The tension free repair introduced by IrwingLichtenstein, caused a dramatic drop in the recurrence rate and became the procedure of choice. Looking behind our backs we can clearly realize that although evolution of herniology has been going on for centuries, it is only the last 2 decades ${ }^{\text {ee }}$ advances that have catapulted the unsatisfactory results of groin hernia repair in the past to the excellence prevalent today. The profound understanding of the functional anatomy and pathophysiology of the abdominal wall and the inguinal canal has helped reach this end. The present dayes hernia surgeon's armamentarium is full with myriad of surgical techniques ranging from the Lichtenstein repair to laparoscopic hernia repair. This availability of various options has helped the surgeon choose a repair that will best fit with the individual needs of the patient, which are dictated by anatomical, physiological, medical, occupational and many other factors. The advancement has also resulted in increased responsibility over the surgeon's shoulders. Today's herniology makes it compulsory for every surgeon to be adept in the use of prosthetic materials in different ways, to understand precisely the science of biomaterials- their advantages and disadvantages, possible complications after their use, their prevention and treatment if one occurs. Additionally, the modern era in hernia repair demands the surgeons to be proficient in analyzing outcomes of their own surgeries and in using statistics to evaluate different therapies. He is expected to know exactly his own complication rate such as infection rate and recurrence rate while using various modalities. Thus, he cannot only judge his operative skills in an unbiased manner but also give his apprehensive patients a rational assurance. Also, it will help him in improving his technique with every surgery until he becomes as flawless as one can ever be. The danger of high recurrence rate that had loomed low over the heads of hernia surgeons in the past has been dissipated by the advent of the tension-free prolene mesh inguinal hernia repair. 


\section{International Journal of Science and Research (IJSR) \\ ISSN (Online): 2319-7064}

Index Copernicus Value (2013): 6.14 | Impact Factor (2015): 6.391

\section{Review of Literature}

\section{HISTORICAL ASPECT ${ }^{27,49}$}

The term hernia is derived from Greek ,hernios ${ }^{\text {ee }}$ meaning an offshoot or bud while in Latin the word means a tear or rupture. The earliest mention of hernia is found in an Egyptian papyrus (Ebers,1550 B.C.), which describes bandaging (trussing), cathartics and hot poultices as modes of its treatment. Greek and Phoenician statuary vividly depicted hernias. Celsus, the encyclopedist in A.D. 25 described transillumination test and correctly differentiated hernia from hydrocele. He was $1^{\text {st }}$ to describe an operation for painful hernias. The operation included an incision over scrotum just below the pubis with removal of the hernial sac along with testis at external inguinal ring. The wound was left open to heal with scar formation. Also, he recommended "taxis" as treatment for strangulated hernia. Galen in A.D.200 advocated the concept of rupture of peritoneum along with stretching of the overlying fasciae and muscles as the cause of herniation. Paul of Aegina (A.D.700) refuted this theory stating that the peritoneum need not have to rupture but could stretch to form a hernia. He was the one to differentiate between incomplete inguinal herniation and the complete scrotal form.

Although, the anatomical knowledge of inguinal canal accumulated and pathophysiology of herniation partially unveiled, the surgeries for repair of hernia inevitably led to infection and recurrence was more a rule than exception. This was the cause that non-operative measures such as taxis, ice or warm baths, enemas, purgatives, sclerosant injections came in vogue with equally frustrating results. In such a gloomy situation Joseph Lister brought about a revolution in medical science with his discovery of antiseptic techniques. It was a giant step for mankind when Lister successfully treated an open fracture of tibia with undiluted carbolic acid dressings and demonstrated its antiseptic properties. Marcy, Lister"s $1^{\text {st }}$ American pupil was the $1^{\text {st }}$ surgeon to perform aseptic herniorrhaphy in which he reduced 2 incarcerated direct inguinal hernias above external inguinal ring that was sutured deeply. In 1874 Steele (England) sutured the external ring to the spermaic cord with the hope of tightening of external ring. Czerny (Germany) in 1876 performed the $1^{\text {st }}$ formal herniotomy i.e. pulling the sac, ligation at neck, excising the sac and allowing the neck to retract. In 1879, Kocher transplanted the twisted sac anterolateral ${ }^{\wedge}$ with a suture passing through external inguinal ring. LucasChampionniere of France (1885) has the credit to be the first to split the external oblique aponeurosis and lay open the inguinal canal.

At the same time, depressing results of hernia repair were published by Billroth (1890) and Bull (1891). According to the analyzed data, the mortality from sepsis, peritonitis, hemorrhage and various operative errors was $2-7 \%$. The recurrence rate within a year was $30-40 \%$ and at the end of 4 years $100 \%$.

EdoardoBassini: Born (1844) and educated in Pavia, Italy he became Professor of Surgery in Pauda. EdoardoBassini single handedly turned this tide of failures in repair of inguinal hernia by introducing an operation that became the basis of modern herniorrhaphy..

\section{Need for the Study}

The fear of recurrence haunting the general surgeons all over the world made them think of various homografts, heterografts and biomaterials that possibly could strengthen the posterior wall of the inguinal canal.Different biomaterials such as steel wire, nylon mesh, and tantalum gauze were tried and later discarded due to various complications.The real breakthrough came when Usher successfully used Marlex mesh in hernia repair in 1956. Though Usher limited used of mesh only in cases of recurrent, large direct and sliding hernias, the science of meshplasty evolved rapidly and has now become the gold standard in management of inguinal hernia. The tension-free concept got its breakthrough when Irving Lichtenstein (1920-2000) from Los Angeles realized that tension-free repair can be achieved by using prosthetic material to bridge the gap between the muscular and ligament tissues. A modest attempt is made here to give account of tension free prolene mesh hernia repair and our own experience with open tension-free repair using prolene mesh.

\section{Materials and Methodology}

\section{Material}

The present study comprises all adult cases of inguinal hernia in whomprolene mesh hernioplasty was done in the Department of General Surgery at Krishna Institute of Medical sciences, Karad between the period of November 2013 to June 2015. The follow up was done on O.P.D. basis till October 2015. Most of the operated patients turned up regularly for the follow up after the operation. Those, who could not attend the O.P.D. on the prescribed date, were contacted by means of either telephone or personal letters and were requested to visit the O.P.D. at the earliest. In our study all 50 patients with 55 inguinal hernias (five patients had bilateral hernias and were operated on both sides) were treated with prolene mesh hernioplasty.

\section{Method}

\section{Selection criteria:}

- Prolene mesh hernioplasty was performed in all types of adult inguinal hernias and hernias in all stages (i.e. reducible,obstructed etc..) Recurrent hernias were also included.

- The patient or his close relatives were first briefed about prolene mesh hernioplasty, its advantages and possible complications. Only those patients underwent prolene mesh repair of inguinal hernia that voluntarily accepted this modality of treatment.

- No associated problems such as chronic obstructive pulmonary disease, benign enlargement of prostate, old age, obesity or heart disease were considered as contraindication to the procedure.

\section{Inclusion Criteria}

1) Adults $>20$ years age

2) Direct hernia

3) Indirect hernia

4) Recurrent hernia due to non mesh repair

Exclusion Criteria

1) Hernia in Children 2) Strangulated hernia 


\section{International Journal of Science and Research (IJSR) \\ ISSN (Online): 2319-7064 \\ Index Copernicus Value (2013): 6.14 | Impact Factor (2015): 6.391}

\section{Preoperative preparation}

In most patients preoperative investigations were performed on O.P.D. basis. Anaemia, if found was corrected. Newly detected diabetic patients were started on oral hypoglycemics or injectable insulin as per physician "s advice. Patients with heart disease were treated accordingly except that aspirin was discontinued for 10 days preoperatively. All elective patients were admitted on the day before surgery. Diabetic and hypertensive patients were asked to continue their normal regime. The patients who underwent elective surgery under spinal anaesthesia were kept nil by mouth overnight. Operation site was shaved. Morning dose of antihypertensives were administered while morning dose of insulin or oral hypoglycemic were omitted. Preoperative antibiotics were not prescribed.

Anaesthesia: Spinal anaesthesia was used in all the cases.

\section{Operative Technique}

Initial dissection: A standard inguinal incision was deepened down to the external oblique aponeurosis. The superficial epigastric vessels were carefully ligated or cauterized to prevent postoperative haematoma formation. Inguinal canal was opened by incising external oblique aponeurosis. The spermatic cord was mobilized and hernial sac separated from the cord by blunt dissection.

Hernia sac: Direct sacs were only pushed gently to return their contents into the abdominal cavity. Indirect sacs were dissected up to extra peritoneal fat. The sacs were opened, contents were reduced and the sacs were excised after transfixing their necks.

Onlay mesh: A prolene mesh of an appropriate size (3" * 6 ") and shape was first soaked in an antibiotic solution (ciprofloxacin).The mesh was then placed over the posterior wall of inguinal canal. It was slit longitudinally partway from lateral to medial to give 1/3 lower leaf and 2/3 upper leaf. The mesh must be wide enough to ensure that it can be tucked well up under the superior leaf of the external oblique and that its lower edge reaches or overlaps the inguinal ligament. The first stitch was taken at the infero-medial corner of the mesh that anchored it to the periosteum over the pubic tubercle. It is critically important to obtain $2-3 \mathrm{~cm}$ overlap here as pulling away laterally of the medial corner of the mesh from the pubic tubercle has been proposed as a cause of recurrence. The inferior margin of the mesh was sutured loosely to the incurved part of the inguinal ligament with simple interrupted sutures. The medial margin was sutured to the anterior rectus sheath while the superior margin was sutured to the conjoint tendon and the internal oblique muscle. One or two sutures were used where the tails of the mesh cross lateral to the spermatic cord and were placed to ensure a snug fit around the cord forming a new deep ring. Suture material used was no. 1 prolene, and 6-7 knots were tied to prevent its loosening. The spermatic cord was replaced in the inguinal canal and the wound was closed in a routine fashion. Aseptic dressing was done and scrotal support was given to prevent oedema formation.

Postoperative management: The patients were started on liquids about 4 hours after the surgery and soft diet was given in the night. Injectable Taxim (1gm iv 12 hourly) was the preferred antibiotic and was given till 2nd postoperative day. Oral Tab.Taxim O $200 \mathrm{mg}$ twice daily was given for another 5 days starting from 3rd postoperative day. Analgesics were administered on demand basis. Dressing was opened on 3rd postoperative day and suture line checked for any serous collection, haematoma formation or signs of infection such as tenderness, raised local temperature and redness. All the patients were ambulated from the 1st postoperative day and ambulation was continued thereafter. Patients were encouraged to use toilet by themselves and stroll in the corridors. Only precaution taken was application of scrotal support to prevent scrotal oedema. Most of the patients were discharged on 3rd postoperative day. The patients were advised to return to the surgery O.P.D. after 7 days to get the surgical site examined. Thereafter, they were asked to come for follow up on monthly basis to which most of the patients complied. Most of the patients were advised to return to work and resume normal activities immediately after discharge, though heavy works were prohibited for about one month.

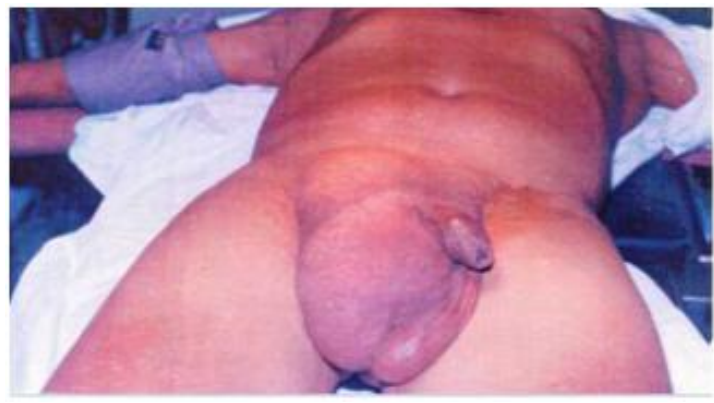

Right sided Complete indirect inguinal hernia

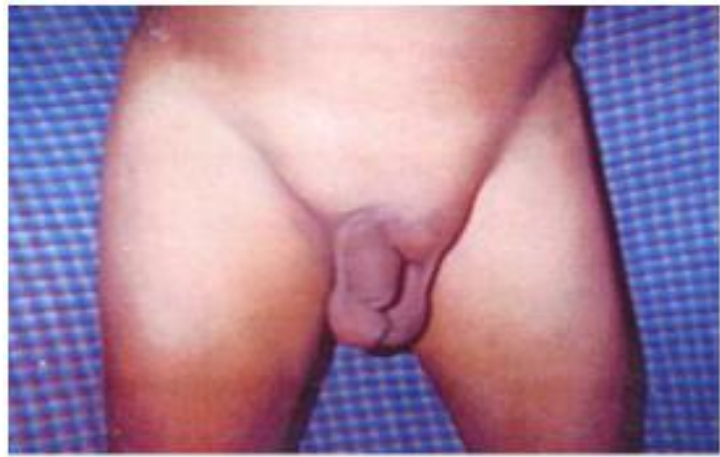

Left Sided incomplete indirect inguinal hernia

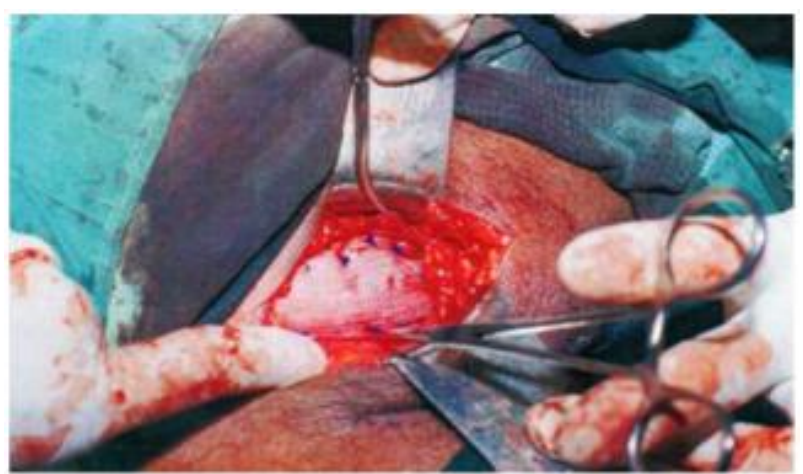

Prolene mesh sutured over the floor of inguinal hernia 


\section{International Journal of Science and Research (IJSR) ISSN (Online): 2319-7064}

Index Copernicus Value (2013): 6.14 | Impact Factor (2015): 6.391

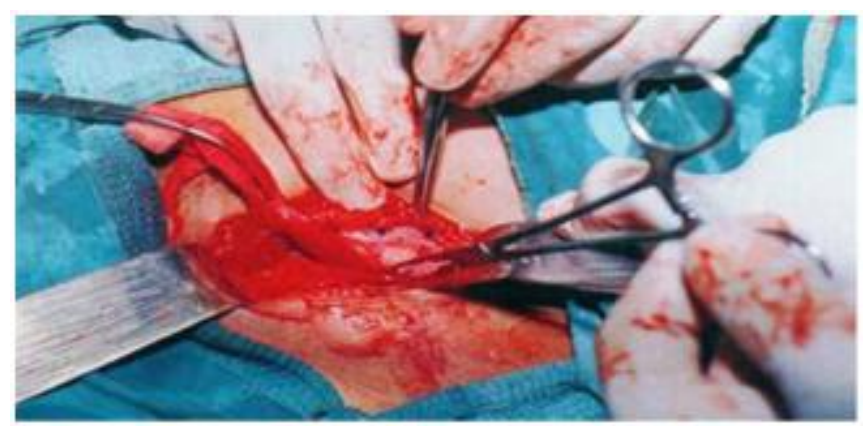

Sutured prolene mesh over posterior wall of the inguinal canal. The spermatic is hooked using a gauze tape.

\section{Results}

Type of Hernias Operated (55 hernias operated on 50 patients)

\begin{tabular}{|c|c|c|c|c|}
\hline Type & Unilateral & Bilateral & Total no. of hernias & Percentage \\
\hline Direct & 12 & $4(8$ hernias) & $20(12+8)$ & $36.36 \%$ \\
\hline Indirect & 31 & 1 (2 hernias) & $33(31+2)$ & $60 \%$ \\
\hline Pantaloon & 1 & 0 & 1 & $1.82 \%$ \\
\hline Recurrent & 1 & 0 & 1 & $1.82 \%$ \\
\hline Total & 45 & 5 (10 hernias) & 55 & $100 \%$ \\
\hline
\end{tabular}

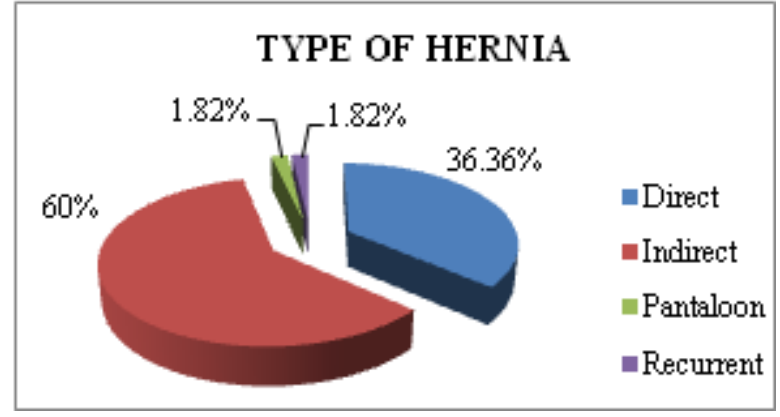

In this study out of 50 patients, 5 patients had bilateral inguinal hernias out of which 4 patients had bilateral direct inguinal hernias and 1 patient had bilateral indirect inguinal hernia. Majority hernias that were operated were indirect inguinal hernias (33 i.e 60\% ), Twenty (36.36\%) operated hernias were of direct type, while one (1.82\%) pantaloon and one $(1.82 \%)$ recurrent inguinal hernias were subjected to prolene mesh repair. In all 55 hernias were operated upon.

Early postoperative complications ( $<1$ months) in 55 repairs

\begin{tabular}{|l|l|l|}
\hline Complication & No. of patients & Percentage \\
\hline Mortality & 0 & 0 \\
\hline Septicaemia & 0 & 0 \\
\hline Haematoma & 0 & 0 \\
\hline Infection (Localized) & & \\
a) subcutaneous & 1 & $1.82 \%$ \\
b) deep & 0 & 0 \\
c) abscess & 0 & 0 \\
\hline Thromboembolism & 0 & 0 \\
\hline Testicular pain / swelling & 1 & $1.82 \%$ \\
\hline
\end{tabular}

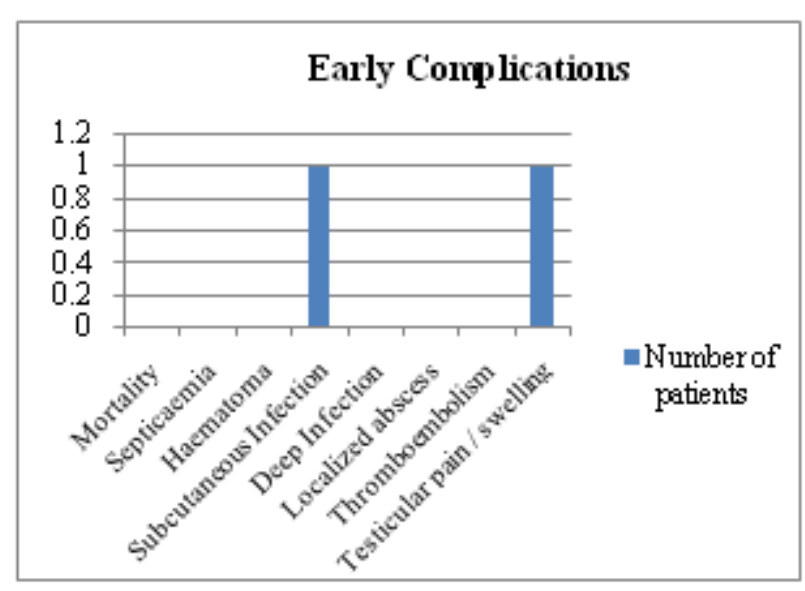

Late postoperative complications ( $>1$ month)

\begin{tabular}{|l|l|l|}
\hline \multicolumn{1}{|c|}{ Complication } & No. of patients & Percentage \\
\hline Pain & 1 & \\
a) $<2$ months & $1.82 \%$ \\
b) $>$ 2months & 0 & 0 \\
\hline Late infection & 0 & 0 \\
\hline Testicular atrophy & 0 & 0 \\
\hline Recurrence & 0 & 0 \\
\hline
\end{tabular}

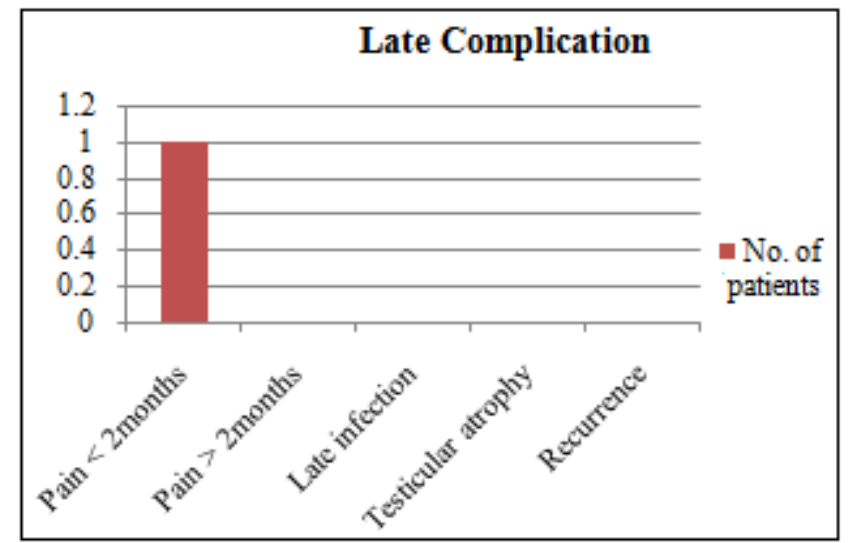

In this study one (1.82\%) patient developed localized subcutaneous infection after prolene mesh repair of his left sided Direct inguinal hernia. The patient was diabetic and the wound healed with regular dressings. In our study only one (1.82\%) patient developed testicular pain and swelling on $3^{\text {rd }}$ postoperative day. The pain was not due to orchitis. Both the testes on examination were found to be normal. On examination cord oedema was present. Scrotal oedema was the cause of testicular pain and swelling. Continued scrotal support resolved this problem and the patient was discharged on 3rd postoperative day as was the routine without any further sequel. Out of 55 hernia repairs in 50 patients only one $\left(1.82^{\circ} \%\right)$ patient in our series had pain in operative region that lasted for more than one month. Only nonsteroidal analgesics sufficed to deal with this problem and no patient complained of pain after 2 months of surgery. No patient in our series developed late infection or testicular atrophy. No recurrence was noted during the period of follow-up.

\section{Duration of stay in hospital}

\begin{tabular}{|c|c|c|}
\hline Days & Number of patients & Percentage \\
\hline 3 & 49 & $98 \%$ \\
\hline $3-5$ & 1 & $2 \%$ \\
\hline$>5$ & 0 & 0 \\
\hline
\end{tabular}




\section{International Journal of Science and Research (IJSR) \\ ISSN (Online): 2319-7064}

Index Copernicus Value (2013): 6.14 | Impact Factor (2015): 6.391

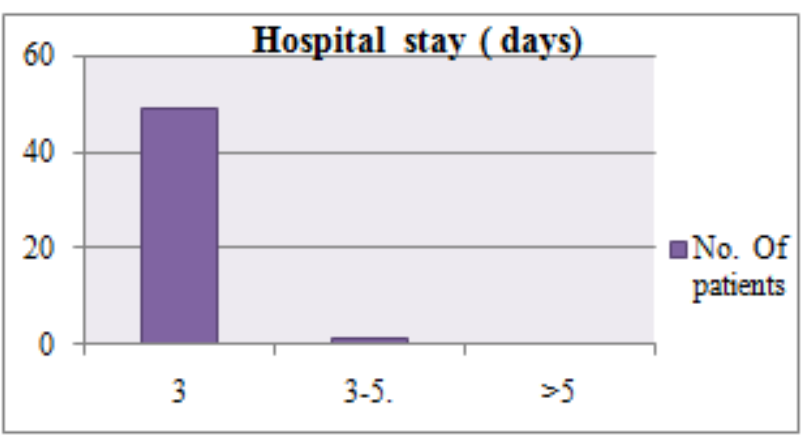

Majority of the patients (49 i.e 98\%) in our study were discharged on $3^{\text {rd }}$ postoperative day. The patients were admitted a day prior to surgery to get the pre-anaesthetic checkup done and were posted for surgery next day. One (1.82\%) patient who had developed localized subcutaneous infection required suture removal and dresssing after which the wound was left open to heal by secondary intention and patient visited OPD for regular dressings. This patient had to stay in hospital for 5days which was the longest hospital stay in our series and almost twice the routine hospital stay.

\section{Duration of follow up}

\begin{tabular}{|c|c|}
\hline Duration in months & No. of cases \\
\hline $0-6$ & 50 \\
\hline $7-12$ & 26 \\
\hline $13-18$ & 20 \\
\hline $19-23$ & 9 \\
\hline
\end{tabular}

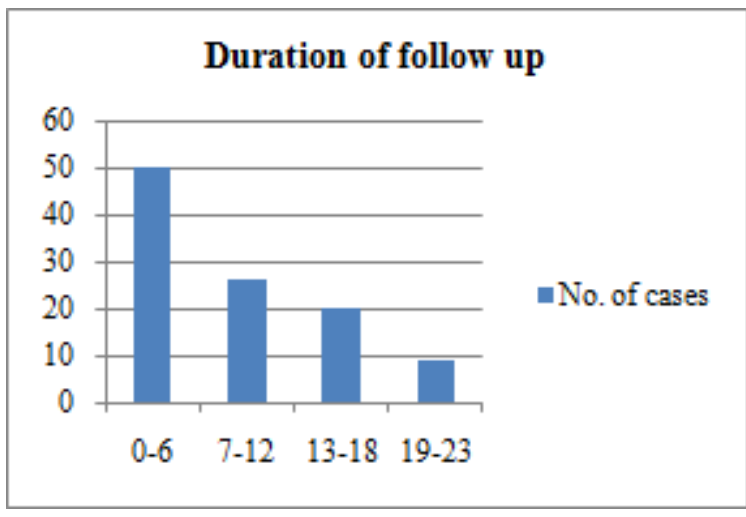

All 50 cases were followed up for first 6 months. The patients were followed for the maximum possible period within the confines of the duration of this study, which was 2 years. Thus in all 50 operated hernia cases were followed up.

\section{Discussion}

\section{The Lichtenstein Repair}

Although Lichtenstein advocated and used prolene mesh to bolster the repairs of both direct and recurrent hernias in 1970s, his suggestions were neither popular nor generally accepted. Lichtenstein was first to coin the term "tensionfree hernioplasty" in the second edition of his book "Hernia repair without disability" in $1986 .{ }^{34}$ Using this technique he operated upon 1000 patients with minimal complications and zero recurrence rate after follow up of between 1-5 years. ${ }^{36}$ Everybody was awestruck! Attempts were made to belittle the procedure and derogatory criticism was inflicted on the results. Now, about 2 decades later the repair has become gold standard in hernia surgery. Even in the hands of non-expert surgeons this procedure has given excellent results. In this study we have used the Lichtenstein 's tension free mesh repair, only one patient developed localized subcutaneous infection and there was no recurrence noted in our study.

This fact is proved by the results of survey of about 72 surgeons who performed 16,000 tension-free mesh repairs of inguinal hernias with a recurrence rate less than $0.5 \%$ and infection rate of $0.6 \%{ }^{62,65}$

\section{Indications}

Virtually all direct, indirect and recurrent adult hernias can be repaired by this procedure. Prior to publication of Lichtenstein"s report surgeons using prosthetic mesh in hernia repair had reserved it for large direct, large sliding or recurrent inguinal hernias only. For fear of infection mesh was used only when absolutely necessary. In cases of indirect hernias herniotomy and traditional herniorrhaphy was considered adequate. But Shulman et al reasoned that direct hernias might appear in later life in a large number of patients who had had operation for their indirect hernias and prophylactic reinforcement of posterior wall of inguinal canal could save such patients from another surgery. This view is broadly accepted now. ${ }^{65}$

Similarly, no systemic disease is considered a contraindication to this repair. Opinions, however differ in case of hernias resulting from connective tissue disorders (Marfan's and Ehlers-Danlos syndromes) with Wantz ${ }^{78}$ considering it a contraindication while Shulman et al maintain that the recurrence rate of traditional repair in such cases is very high and can be brought down by using mesh repair.

In our study all adult patients were subjected to tension-free prolene mesh hernia repair irrespective of any ailment present as long as they were willing.

\section{Salient features of the Lichtenstein's repair ${ }^{29}$ :}

- Local anaesthesia

- Adequate size of prolene mesh

- Attachment of the infero-medical corner of the mesh well overlapping $(2-3 \mathrm{~cm})$ the pubic tubercle.

- Attaching the mesh with either loose continuous or interrupted sutures (to prevent tissue necrosis) superiorly high up under upper leaf of the external oblique aponeurosis, inferiorly to the inguinal ligament.

- Lateral tails of the mesh are overlapped to provide a snug fit around the cord. This constructs new deep ring that prevents future possibility of a new primary indirect hernia growing lateral to the cord.

- Encouragement of early mobilization.

- Discharge about 2 hours later (or on passing urine).

All these steps are crucial in the success of the Lichtenstein's repair, but the most important factor perceived is overlapping of about $2-3 \mathrm{~cm}$ of pubic tubercle by the prolene mesh as the mesh pulling away laterally from the pubic tubercle is generally considered as the reason of recurrence. 


\section{International Journal of Science and Research (IJSR) \\ ISSN (Online): 2319-7064 \\ Index Copernicus Value (2013): 6.14 | Impact Factor (2015): 6.391}

In our study we had to modify few features but care was taken not to alter any of the basic principle of the Lichtenstein"s repair. Local anaesthesia could not be used in all patients. This was because many patients were apprehensive and prejudiced against use of local anaesthesia in what they thought as major surgery and preferred spinal anaesthesia instead. We tried to convince all about advantages of local anaesthesia, but finally the patient's preference was respected. Similarly, although early ambulation was given to all patients, the patients were discharged on $3^{\text {rd }}$ post-op day. It is notable to find that even after using spinal anaesthesia none developed urinary retention that required catheterization. Though analgesics were given on-demand basis, the demand was very less proving a relatively painless nature of tension-free meshplasty.

\section{Advantages of the Lichtenstein's repair}

The fear that use of prosthetic mesh in human body especially in groin will give rise to uncontrollable sepsis and eventual rejection of mesh has, fortunately, proved futile. No infection resulted due to the use of prolene mesh in our study. Although one patient developed localized subcutaneous infection, the causative factor behind it was failure of strict aseptic practice. The prolenemesh was not infected and local infection resolved after regular dressings. No mesh removal was required in our study. Various trials, encompassing thousands of meshplasties confirm that the rate of infection is in the range of 0.03 to $0.6 \%$ at the most even in hands of inexperienced surgeons. ${ }^{14}$ It has been proven that length of operating time and skill of the surgeons are the two most important factors contributing to infection. Careful tissue handling, proper haemostasis and thorough aseptic practice may even preclude use of antibiotics and still give infection rate of $0 \%$ (table A).

It is found that major cardiopulmonary and thromboembolic complications are distinctly rare after the Lichtenstein repair. The credit goes to early postoperative ambulation. The use of Spinal anaesthesia also helps in operating elderly frail patients who are otherwise deemed unfit for General Anaesthesia.
In our study, only one patient developed postoperative pain which lasted not more than one month and was relieved by NSAID analgesics. It has been convincingly shown by meta-analysis involving results of 17 trials that incidence of early and long term postoperative pain is considerably reduced after the Lichtenstein's meshplasty. Absence of tension on the sutures might be the responsible factor. This advantage considerably improves the patient"s quality of life in early postoperative period. ${ }^{14}$ The reduction in postoperative pain does not only improve the patient's quality of life but also encourages them to return to work as early as possible. The desk workers, ofcourse start working earlier (median: 7-8 days) than manual workers (median: 12 days). This median time off work is considerably less than that after open nonmesh hernia repair (median: 28-49 days). Diverse factors such as individual patient motivation, nature of work, self- employment, or availability of paid leave influence the time of return to work. In successive studies a decrease in this time is noted which is obviously beneficial to the social economy. ${ }^{14}$

The ease of operative technique and absence of any deep dissection in groin region have resulted in superb results of this repair even in the hands of inexperienced surgeons. ${ }^{62}$ We have already seen that the most successful pure tissue repair i.e. Shouldice $s$ repair (recurrence rate about $0.6 \%)^{61}$ at Shouldice clinic could not be emulated to the perfection by general surgeons all over world due to the complexity of the procedure. The short learning curve noted in the Lichtenstein repair helps even residents in surgery to achieve excellent results comparable to hernia experts. This fact has led to rapid acceptance of this repair among general surgeons.

The most important of all advantages of the Lichtenstein repair is the dramatically low recurrence rate. In our study not even a single patient had recurrence. Various studies have shown the recurrence rate to be $0.2 \%$ and rejection rate of zero (table A). This unprecedented success is certainly the result of clear insight in the pathophysiology of development of hernia and tension-free nature of the repair. The Lichtenstein's repair has paved way for the day when zero recurrence will not be a novelty in hernia surgery.

Table A: Result of the mesh patch repair of inguinal hernias without formal closure of defect ${ }^{65}$

\begin{tabular}{|c|c|c|c|c|c|c|}
\hline Name & Dates (years) & No.of operations & No. of infections & No. of rejections & No. of recurrences & \%of recurrences \\
\hline Martin RE & $1976-1984$ & 550 & 0 & 0 & 0 & 0 \\
\hline Barnes JP & $1976-1989$ & 271 & 0 & 0 & 0 & 0 \\
\hline Capozzi JA & $1978-1988$ & 745 & 0 & 0 & 4 & 0.54 \\
\hline Tinckler LF & $1980-1985$ & 392 & $1(0.25)$ & 0 & 3 & 0.77 \\
\hline Lichtenstein IL & $1984-1989$ & 1552 & 0 & 0 & 2 & 0.13 \\
\hline
\end{tabular}

In our study even if the sample size was very small (55 hernias repaired) most of the advantage of the Lichtenstein"s repair were replicated.

No patient in our study developed postoperative thromboembolic complication. This finding is consistent with previously published reports. The postoperative pain was also very less in our patients. As already mentioned analgesics were prescribed only on-demand basis and majority of patients were comfortable without analgesics. This proves the painless nature of the tension free repair.
The operative technique was quite simple and after performing a few repairs (2-3 in number) under guidance of consultants, the residents were quite confident and comfortable about the surgery.

\section{Complications of Prolene Mesh Repair Of Inguinal Hernia:}

Irrespective of use of prolene mesh many complications are prevalent in inguinal hernia repair. Although it is impossible to abolish them altogether, vigilance against technical errors and proper tissue respect can bring the complication rate to 


\section{International Journal of Science and Research (IJSR) \\ ISSN (Online): 2319-7064 \\ Index Copernicus Value (2013): 6.14 | Impact Factor (2015): 6.391}

minimum. Following are a number of complications which, if occur unfortunately, may leave the surgeon to face extremely unhappy patients.

\section{1] Infection ${ }^{12}{ }_{-}{ }^{79}$ :}

Although it was thought previously that the prolene used in hernia repair would act like a foreign body and there would ensue uncontrollable sepsis, these fears have proved futile in face of the hard data available. It has been shown conclusively that the prolene mesh is biochemically inert and does ignite minimal foreign body reaction. Also, the predictions that bacteria will launch in the interstices of the mesh and will cause sepsis have proved wrong.

A few precautions taken intraoperatively do result in satisfactorily low infection rate. Blood is a medium in which bacteria flourish so meticulous haemostasis is must. Excessive use of electrocautery devitalizes tissue and may predispose to infection, so should be avoided. A large number of trials including thousands of patients have revealed a very low infection rate in hernia repair using prolene mesh (table A). Many of these studies have not used prophylactic antibiotics at all. ${ }^{73}$ In case of infection use of antibiotics and opening of the wound for free drainage generally suffice to settle the problem. In such scenario the mesh should not be exposed. Fulminant sepsis making the mesh removal mandatory is fortunately rare.

In this study this complication was encountered in only one patient who developed a localized subcutaneous infection. The collection was drained and wound was left open to heal by secondary intention. No additional treatment was required except regular dressings. No mesh removal was required in our series.

\section{2] Ischaemicorchitis and testicular atrophy ${ }^{79}$ :}

Although incidence of acute ischaemicorchitis is very low $(<1 \%)$ in primary hernia repairs, the incidence increases in repair of recurrent hernias (as high as 5\%) and in large complete indirect or direct scrotal hernias (2.5\%).

The patient presents with painful, tender and swollen testicle associated with fever about 2-3 days postoperatively. Although the fever subsides early, testicular pain and swelling persist. In fortunate patients the inflammation resolves spontaneously but in about $1 / 3$ patients it progresses till the testicle becomes atrophic which may take up to 12 months. Gangrene of the testicle is rare.

Many factors such as interruption of the testicular blood supply by tightly reconstructed deep or external inguinal rings or an anomalous blood supply to the testicle are proposed to be responsible for this complication. However, it seems that extensive dissection in an attempt to free the hernial sac form the spermatic cord is the main culprit. This may not only injure the testicular artery but also traumatize delicate veins of pampiniform plexus resulting in venous insufficiency. High incidence of ischaemicorchitis in repair of massive scrotal hernias supports this etiology. As no reliable treatment except for antibiotics and antiinflammatory drugs is present, every attempt should be made to prevent the occurrence of this complication. To divide the large indirect sac near deep ring and leave the distal sac in situ without any attempt to dissect it away from the cord is a viable option and has proved successful in preventing this complication. In every case care should be taken to avoid the dissection of the spermatic cord distal to the pubic tubercle. This results in preservation of collateral circulation to the testicle. Unfortunately, in cases with large indirect sliding inguinal hernias it becomes necessary to extensively dissect the sac to reduce abdominal contents that form part of its wall. Same is the case for large direct hernias that descend into the scrotum. In such patients the possibility of the complication should be explained to the patients and close relatives preoperatively and written consent for orchidectomy should be obtained even though orchidectomy is seldom required.

In our study no case developed ischaemicorchitis or testicular atrophy. We never dissected the spermatic cord beyond the pubic tubercle. We had 10 hernias (18.18\%) descending into the scrotum. In all of them the sac was divided near deep ring and distal portion of the sac was left in situ taking care to keep open the cut end of the distal sac in order to prevent future development of hydrocele.

\section{3] Haematoma ${ }^{79}$ :}

It can follow any surgical procedure and is not specific for inguinal hernia repair. Inadequate haemostatis during operation and slippage of ligature in immediate postoperative period are the main causes. It can form in inguinal region or blood can gravitate in scrotum forming scrotal haematoma. If secondarily infected it may form an abscess and increase the patient's morbidity considerably. Timely evacuation is the treatment of choice to prevent further morbidity. In this study, no patient developed haematoma post-operatively.

\section{4] Groin pain ${ }^{8,79}$ :}

Persistent groin pain after inguinal hernia repair was troublesome in pure tissue repairs and suturing under tension was held responsible for it. Now with advent of tension free meshplasty this problem has almost become extinct. This is clearly evident from our study in which very few patients, if ever asked for analgesics postoperatively and none had to visit the O.P.D. for complaint of groin pain. Decrease in postoperative pain has played a significant role in rapidly returning the patients to routine daily activities and work. Few other causes of postoperative groin pain are described such as femoral and ilioinguinal nerve entrapment, neuroma formation and periostitis of the pubic tubercle. These causes are rare and during our study we did not encounter a single such case.

\section{5] Thromboembolism ${ }^{79}$ :}

Although common in Cooper's ligament repair, occurrence of this complication is extremely rare in the routinely performed Lichtenstein's repair. Immediate postoperative ambulation further reduces scope of this problem. No patient in our series developed thromboembolism or any major associated cardiovascular problem. 


\section{International Journal of Science and Research (IJSR) \\ ISSN (Online): 2319-7064 \\ Index Copernicus Value (2013): 6.14 | Impact Factor (2015): 6.391}

6] Mortality ${ }^{79}$ :

Mortality as such is extremely rare in hernia surgery and almost always associated medical or surgical problems. There was no mortality in our study.

\section{7] Other complications:}

Numbness and paresthesia in the region of incision, due to stretching of ilioinguinal nerve and paresis of quadriceps muscles due to femoral nerve injury are infrequently reported. Careful handling and preservation of nerves intraoperativelyelimate problems of this sort. Similarly, inadvertent injury to bladder, bowel and ureter may occur during repair of large direct, indirect or sliding hernias. Gentle handing of the viscera during repair is the only thing needed to prevent such complications.

Transection of the vas deferens may occur occasionally and requires end-to-end anastomasis with fine nonabsorbable sutures. We did not encounter any such complications in this study.

\section{8] Recurrence ${ }^{4}$ :}

Recurrence after inguinal hernia repair has proved the most frustrating complication and has stimulated continuous research in the filed of hernioplasty. „Bulge or weakness in the operation areas exacerbated by a valsalva maneuver necessitating further operation or provision of a truss ${ }^{\text {ee }}$ can be a simple definition of recurrence. Although a recurrence rate of $10-15 \%$ was found in the period when pure tissue repairs were in vogue, the rate has decreased considerably with advent of tension-free mesh repair of inguinal hernia. Many series studying thousands of meshplasties have reported recurrence rates of $<1 \%$ and some studies have succeeded in obtaining even zero recurrence.

It is generally observed that technical failure, undue tension on the suture line, missed hernia and infection are responsible for early recurrences that appear within first 1-2 years. Thereafter tissue weakness or failure and acquired hernia are the causes of recurrence. Now that the Lichtenstein repair, mesh repair have succeeded in this respect we can hope for a future when recurrent hernia will be an extinct entity.

In our study of 55 hernias in 50 patients we have not encountered a single recurrence.

\section{Conclusion}

The role of prolene mesh in repair of inguinal hernias has expanded considerably over last 2 decades. Although, various techniques using prolene mesh such as mesh-plug technique, preperitoneal mesh placement are rapidly evolving, the Lichtenstein repair has become gold standard in hernia surgery, proving superior to traditional pure tissue repairs of hernia. The repair is physiologically sound as it buttresses the posterior wall of the inguinal canal, weakness of which is the reason behind development of inguinal hernia. Prolene mesh repair does not result in higher rate of infection. Infection is directly related to operative technique. Tension-free nature of the repair, which we used, results in reduced pain in postoperative period. This in turn helps in early resumption of routine duties by the patient. Also we could not find a single case of recurrence. Considering the wide range of advantages this repair secures for the patient the cost of the prolene mesh seems nominal only.

\section{References}

[1] Adler RH. An evaluation of surgical mesh in the repair of hernias and tissue defects. Arch Surg 85, 1962:836.

[2] Alexandre JH, Bouillot JL, Aouad K. Le Journal de CarlioChirugie 1996; 1953- 1959

[3] Arnbjornsson E. Development of right inguinal hernia after appendectomy. Am. J. Surg., 143,1982:174.

[4] Balen EM, Fgerrer JV, Vincete F et al. Recurrences after prosthetic repair of inguinal hernias by the Lichtenstein repair. Hernia. 4, 2000: 85-87

[5] Berliner SD. An approach to groin hernia. Surg. Clin North Am 64(2), 1984: 197- 213

[6] Cannon DJ, Read RC. Metastatic emphysema: A mechanism for acquiring inguinal herniation. Ann. Surg., 194, 1981: 270.

[7] Colin JF, Elliot P, Ellis H. The effect of uraemia upon wound healing. An experimental study. Br. J. Surg., 66, 1979:793.

[8] Condon RE. Groin pain after hernia repair. Ann Surg 2001: 233-238

[9] Condon RE. Surgical anatomy of the transversusabdominis and transversalias fascia. Ann Surg. 1971:173

[10] Corbitt JD Jr. Transabdominal peritoneal herniorrhaphy. Surg. Laparosc Endosc.3, 1993:328-332

[11]Decher GAG, DJ Du Plessis. The groin and scrotum. In chapter 10. Lee McGregor's synopsis of surgical anatomy. 12th Ed. Bombay; K.M. Varghese Co; 1986:125

[12]Deysine M. Pathophysiology prevention and management of prosthetic infections in hernia surgery. SurgClin North Am. 78, 1998: 1105-1115

[13] Engeset J, Youngson GG. Ambulatory peritoneal dialysis and hernia complications. Surg. Clin. North Am., 64:385, 1984.

[14]EU Hernia Trialists Collaboration. Repair of groin hernia with synthetic mesh. Meta-analysis of randomized controlled trial. Ann Surg. 235, 2002:322332

[15] FogelsonSj, Jackson CR. The repair of tissue deficient hernias by aortic implants. SurgGynecol Obstet. 109, 1959:245.

[16] Ger R. The laparoscopic management of groin hernias. ContempSurg 39(4), 1991:15-19

[17] Gilbert Al. An anatomic \& functional classification for the diagnosis and treatment of inguinal hernia. An J Surg 1989; 157:331-333.

[18] Gilbert Al. Sutureless repair of inguinal hernia. Am J Surg 163, 1992:331-335.

[19] Gomez J, Wylie JH, Ponka JL, Epidermoid carcinoma in a cutis graft after repair of an incisional hernia Rev. Surg. Arch Surg 29,1972:381.

[20] Grant AM. Laparoscopic versus open groin hernia repair :meta analysis of randomized trials based on individual patient data. The EU Hernia Trialists Collaboration Hernia 6(1), 2002:2-10 


\section{International Journal of Science and Research (IJSR) \\ ISSN (Online): 2319-7064}

Index Copernicus Value (2013): 6.14 | Impact Factor (2015): 6.391

[21] Gullmo A, Broome A, Smedberg S. Herniography. Surg. Clin. North Am. 64,1984:229.

[22] Halverson K, McVay CB. Inguinal \& femoral hernioplasty. Arch Surg 101, $1970: 127-135$.

[23] Heikkinen Y, Haukipuro K, Leppala J et al . Total costs of laparoscopic and Lichtenstein inguinal hernia repairs: a randomized prospective study. Surg. LaparoscEndosc. 7(1), 1997:1-5

[24] Hoffman HC, Traverso ALV. Preperitoneal prosthetic herniorrhaphy; one surgeon "s successful technique. Arch Surg. 128, September 1993: 964-970

[25] Hughson W, The persistent or preformed sac in relation to oblique inguinal hernia. Surg. Gynaecol. Obstet; 41, 1925: 610.

[26] Inderbir Singh In Chapter 16, Human Embryology, 6th Ed India : McMillan India Ltd. 1996; 286-289.

[27] Jack Abrahmson. Hernias. In :Zinner MJ, Schwartz SI, Ellias H eds. Maingot's abdominal operations, 10th Ed. Singapore: McGraw Hill Book Co, 2001;479

[28] Jan TC, Wu CC, Yang CC, Lee YM. Detection of open processusvaginalis by radionuclide scintigraphy. Kao Hsiung I HsuehKoHsuehTsaChih 8, 1992:54.

[29] Kark AE, Kurzer MN, Belsham PA. Three thousand one hundred seventy five primary inguinal hernia repairs. Advantages of ambulatory open mesh repair using local anesthesia. Journal of the American College of Surgeons. 186(4), April 1998:447-456.

[30] Keith A. On the origin and nature of hernia. Br. J. Surg.,11, 1924: 455.

[31] Klosterhalfen B, Junge K, Hermann "s B, et al. Influence of Implantation interval on the long term biocompatibility of surgical mesh. Br J Surg 89, 2002:1472- 1480.

[32] Koontz AR. On the need for prosthesis in hernia repair. Am Surg 28, 1962:342

[33] Kugel RD. The Kugel repair for groin hernias. SurgClin North Am. 83(5) October 2003: 1119-1139

[34] Lichtenstein IL, Hernia repair without disability. 2nd Ed. St Louis, Tokyo: IshiyakuEuroamerica, Inc. 1986.

[35] Lichtenstein IL, Shore JM. Simplified repair of femoral and recurrent inguinal hernias by a "plug" technique Am J Surg. 128, 1974:439-445.

[36] Lichtenstein IL, Shulman AG, Amid PK, et al. The tension-free hernioplasty. Am J. Surg. 1989:188-193.

[37] Lichtenstein IL. Herniorrhaphy: personal experience with 6321 cases. Am J Surg 153,1987: 553-559.

[38] Mason MS, Raaf J. Use of homologous dura mater in the repair of hernias. Arch Surg. 82, 1961:856

[39] McKernan JB, Laws HL. Laparoscopic repair of inguinal hernias using a totally extra-peritoneal prosthetic approach. Surg. Endosc. 7, 1993: 26-28

[40] McVay CB. Groin Hernia Cooper ligament repair. In Nyhus LM, Condon RE, eds. Hernia 3rd ed. Philadelphia: JB Lippincott Co., 1989; 119-138

[41] Merritt W, Peacock EE Jr, Chvapil M. Comparative biology of fascialautografts and allografts. Surg Forum. 25, 1974: 524.

[42] Nyhus LM, Stevenson JK, Listerub MB, Harkins HN. Preperitonealherniorrhaphy. West J SurgObstet\&Gynecol 67, 1959: 48-54.

[43] Nyhus LM. Individualization of hernia repair: A new era. Surgery 114, 1993:102.
[44] Paganini AM, Lezoche E, Carle F. A randomized controlled, clinical study of laparoscopic vs open tension free inguinal hernia repair. Surg. Endosc. 12, 1998: 979986

[45] Peacock EE Jr, Madden JW. Studies on the biology and treatment of recurrent inguinal hernia: II Morphological changes . Ann. Surg. 179, 1974:567.

[46] Prolene Mesh - literature of Ethicon Co Ltd.

[47] Prosden JR, Koontz AR. Prosthetic mesh repairs in abdominal wall hernias. Am Surg. 30, 1963:247.

[48] Read RC. Historical survey of the treatment of hernia. In : Nyhys LM, Condon RE eds. Hernia 3rd ed. Philadelphia: JB Lippincott CO, 1989; 5-8

[49] Read RC. The development of inguinal herniorrhaphy. SurgClin. North Am. 64, 1984: 185-196.

[50] Russel RH. The saccular theory of hernia and the radical operation. Surg. Clin. North.Am.,Vol 64; No.3, April 1984.

[51] Rutkow IM. The PerFix plug repair for groin hernias. Surg. ClinNorht Am. 83(45), October 2003: 1079-1098

[52] Rutkow IM, Robbins AW. "Tension-free" inguinal "mesh plug" technique. Surgery ,114,1993:102.

[53] RutkowIm, Robbins AW. "Tension-free" inguinal herniorrhaphy: A preliminary report on the "mesh plug" technique. Surgery, 114(1), July 1993:3-8

[54] Rutkow IM, Robbins AW. Classification of groin hernias. In :Bendavid $\mathrm{R}$, editor, Prostheses and abdominal wall hernias, austin (TX) :RG Landes; 1994.

[55] Rutkow IM, Robbins AW. Mesh plug hernia repair. A follow up report. Surgery 117, 1995:597-598

[56] Rutkow IM. Demographic and socioeconomic aspects of hernia repair in the United States in 2003. Surg. Clin North Am. 83(5), 2003: 1045- 1051

[57] Rutledge RH. Cooper's Ligament Repair: A 25 years experience with a single technique for all groin hernias in adults. Surgery, 103(1), Jan 1998: 1-10

[58] Saunders JM. Repair of inguinal hernia using prolene mesh. Surgery, 110, 1991:430-432

[59] Schumpelick V, Arit G. In: Problems in general surgery. Philadelphia: LippincottRaven Publications; 1995: 5758

[60] Schurz JW, Tetik C, Arregue ME, et al. Complications and recurrences associated with laparoscopic inguinal hernia repair. Prob Gen Surg. 2(1), 1995: 21-25

[61] Shouldice EB. The Shouldice Repair for Groin Hernias, SurgClin North Am 83(5),2003 : 1163-1187

[62] Shulman AG, Amid PK, Lichtenstein IL. A survey of non-expert surgeons using the open tension -free mesh patch repair for primary inguinal hernias. IntSurg 80, 1995:35-6

[63] Shulman AG, Amid PK, Lichtenstein IL. Patch or plug for groin hernia- which? Am J. Surg. 167, March 1994:331-336.

[64] Shulman AG, Amid PK, Lichtenstein IL. The "plug" repair of 1402 recurrent inguinal hernias: A twenty -year experience. Arch Surg. 125, 1990:265-267.

[65] Shulman AG, Amid PK, Lichtenstein IL. The safety of mesh repair for primary inguinal hernias :Result of 3019 operations from five diverse surgical sources.TheAmSurg.58,April1992:255-257.

[66] Simons MP, Kleijnen J, Geldere D, et al. Role of the Shouldice technique in inguinal hernia repairs: a 


\section{International Journal of Science and Research (IJSR) \\ ISSN (Online): 2319-7064}

Index Copernicus Value (2013): 6.14 | Impact Factor (2015): 6.391

systematic review of controlled trials a meta-analysis. Br. J Surg 83, 1996: 734-738

[67] Sinnatamby CS, In Chapter 5, Last's Anatomy Regional and Applied 10th Ed. London Churchill living stone; 1998: 265.

[68] Smith RS. The use of prosthetic materials in the repair of hernias. SurgClin North Am 51, 1973:1387.

[69] Stephenson BM. Complications of open groin hernia repairs. SurgClin North Am 83(5), 2003: 1255-1278

[70] Stoppa R. Hernias of the abdominal wall. In: Chevrel JP, editor, Hernias and surgery of the abdominal wall. Brlin:Springer; 1998; P 171-227.

[71] Strahan AWB. Hernial repair by whole skin graft with report on 413 cases. Br J Surg. 38, 1951:276

[72] Swanstrom LL. Laparscopicherniorrhaphy. SurgClin North Am. 76(3), June 1996: 483-491

[73] Taylor EW, Bryne DJ, Leaper DJ, et al. Antibiotic prophylaxis and open groin hernia repair. World J Surg. 21, 1997: 811-815

[74] Thomas SM, Barnes JP. Recurrent inguinal hernia in relation to body weight. Surg. GynaecolObstet, 1990: 510-512.

[75] Usher FC, Wallace SA. Tissue reaction to plastics. Arch Surg 76, 1958:997.

[76] Usher FC. Hernia repair with Marlex mesh. An analysis of 541 cases. Arch Surg. 84, 1962: 325.

[77] Voitk AJ. The learning curve in laparoscopic inguinal hernia repair for the community general surgeon. Can $\mathrm{J}$ Surg. 41(6), 1998: 446-450

[78] Wantz GE. Experience with the tension-free hernias in men. Journal of the American College of Surgeons. 183, October 1996: 351-356

[79] Wantz GE. Complications of inguinal hernia surgery. SurgClin North Am. 64 (2), April 1984: 287-298

[80] Wantz GE. Giant prosthetic reinforcement of the visceral sac. The Stoppa groin hernia repair. SurgClin North Am.78(6), December 1998:1075-1087.

[81] Zollinger RM Jr. A unified classification for inguinal hernias. Hernia 3, 1999: 195-200 "Synthetic structure of industrial plastics (Book style with paper title and editor)," in Plastics, 2nd ed. vol. 3, J. Peters, Ed. New York: McGraw-Hill, 1964, pp. 15-64.

\section{Author Profile}

Trishant Chotai, PG student MS General Surgery, Krishna Institute of Medical Sciences Deemed University, Karad, Maharashtra, India

V. V. Kanase, MS General Surgery, Krishna Institute of Medical Sciences Deemed University, Karad, Maharashtra. 